\title{
PENINGKATAN KETERAMPILAN BERPIKIR TINGKAT TINGGI (HIGHER ORDER THINKING SKILLS) PADA SISWA SEKOLAH DASAR MELALUI VIDEO BERBASIS KASUS PENCEMARAN LINGKUNGAN
}

\author{
Ilmi Zajuli Ichsan ${ }^{1^{*}}$, Enin Iriani $^{2}$, Farah Muthi Hermawati ${ }^{3}$ \\ ${ }^{1}$ Pendidikan Biologi, FMIPA, Universitas Negeri Jakarta, Indonesia \\ ${ }^{2}$ SD Negeri Jatimulya 02, Bekasi, Jawa Barat, Indonesia \\ ${ }^{3}$ Pendidikan Fisika, FMIPA, Universitas Negeri Jakarta, Indonesia \\ *email: ilmizajuli_bio18s2@mahasiswa.unj.ac.id
}

\begin{abstract}
Learning Natural Sciences on environmental pollution material is one of the important topics. Students at the elementary school level have an important role in protecting the environment around them. This research was conducted with the aim of increasing the Higher Order Thinking Skills (HOTS) of students in science learning in the environmental material. The research method used in this study is Classroom Action Research with details of 3 cycles. The study was conducted during October 2018 at SDN Jatimulya 02 , Bekasi. The number of samples taken was 35 students. The treatment given is by playing case-based learning videos in the classroom. The results showed that there was an increase in HOTS students in science learning using case-based videos. The conclusion is that case-based learning videos can increase HOTS students of SDN Jatimulya 02.
\end{abstract}

Keywords: HOTS, Case-based Learning Video, Environmental learning.

\section{PENDAHULUAN}

Siswa pada tingkat sekolah dasar merupakan siswa yang sedang mengalami masa perkembangan. Mereka tertarik mempelajari hal-hal di sekitar lingkungan tempat mereka tinggal. Siswa tertarik mempelajari lingkungan dikarenakan berkaitan dengan kehidupan keseharian mereka (Dono, Webb, \& Richardson, 2010; Meyer, 2016). Siswa haruslah mempelajari hal-hal di sekitar lingkungan mereka. Siswa yang belum memiliki pemahaman yang baik tentang lingkungan mereka maka akan sulit memahami berbagai permasalahan yang terjadi di lingkungan sekitar mereka. Hal ini membuat pemahaman tentang lingkungan sangat penting dimiliki oleh siswa di berbagai jenjang sekolah (Nesmith et al., 2016; Truelove \& Gillis, 2018).
Permasalahan lingkungan haruslah dicarikan solusi oleh masyarakat. Siswa merupakan salah satu bagian dari masyarakat yang memiliki peranan dalam menjaga lingkungan. Pemecahan lingkungan salah satunya bisa dilakukan dengan cara mengkritisi fenomena lingkungan yang ada. Proses mengkritisi sesuatu termasuk dalam keterampilan abad 21 yaitu Higher Order Thinking Skills (HOTS). Siswa yang memiliki HOTS yang tinggi akan bisa memahami dan mengkritisi berbagai masalah yang ada di lingkungan mereka (Afflerbach, Cho, \& Kim, 2015; Yee et al., 2015). Permasalahannya adalah bahwa HOTS siswa pada tingkat sekolah dasar masih belum terlalu tinggi. Hal ini membuat pembelajaran di sekolah masih cenderung mengedepankan kemampuan menghafal daripada kemampuan yang lebih tinggi. 
Pada pembelajaran di sekolah, guru biasanya hanya mengajarkan materi sesuai dengan konvensional. Sementara itu, pembelajaran abad 21 tidak hanya menuntut siswa memahami konten materi tapi lebih mengarah kepada HOTS (Kivunja, 2014; Motallebzadeh, Ahmadi, \& Hosseinnia, 2018). Hal ini membuat penelitian tentang HOTS ini menjadi penting dikarenakan masih rendahnya HOTS siswa yang ada di jenjang sekolah dasar. Masalah ini sebenarnya sudah sejak lama, tetapi baru mulai menjadi fokus para guru dan peneliti semenjak diberlakukannya kurikulum 2013 dan Ujian nasional dengan komposisi soal HOTS yang banyak. Tujuan dari penelitian ini tentunya untuk mencari solusi peningkatan HOTS siswa SD yang rendah.

Video pembelajaran merupakan sebuah media yang cukup sering digunakan oleh guru. Berbagai jenis video pembelajaran yang biasa ditampilkan oleh guru dalam mengajarkan IPA di SD. Hal itu menjadi menarik, dikarenakan tidak semua jenis video bisa memacu peningkatan HOTS. Video yang diduga dapat meningkatkan HOTS adalah yang berbasis masalah atau kasus, dikarenakan siswa akan terangsang untuk berfikir lebih tinggi tidak hanya sekedar menghafal (Lindfors \& Hilmola, 2016; Sadiqin, Sholahuddin, \& Santoso, 2017).

\section{METODE PENELITIAN}

Penelitian ini dilakukan dengan menggunakan metode penelitian tindakan kelas menggunakan 3 siklus. Setiap siklus mengandung tahapan (1) Perencanaan (2) Pelaksanaan (3) Observasi dan (4) Refleksi. Penelitian dilaksanakan pada bulan September-Oktober 2018 bertempat di SDN Jatimulya 02, Tambun Selatan, Kabupaten Bekasi. Sampel yang digunakan dalam penelitian ini adalah sebanyak 35 siswa kelas
6 SD. Perlakuan yang diberikan yaitu dengan memberikan tayangan video pembelajaran berbasis kasus lingkungan.

HOTS diukur dengan 3 instrumen yang berbeda di setiap siklusnya. HOTS yang diukur disesuaikan dengan taksonomi Anderson yaitu menganalisis, mengevaluasi, dan mencipta (Anderson et al., 2001). Pada siklus 1, materi yang dibahas adalah mengenai pencemaran air. Pada siklus 2, lebih berfokus pada pencemaran udara. Semantara itu, pada siklus 3 pembahasan lebih difokuskan pada upaya penangggulangan pencemaran lingkungan tersebut. Analisis data yang digunakan untuk mengukur peningkatan HOTS menggunakan gain score. Rumus penghitungan gain score menurut Fauziyah \& Jailani (2014) dapat dilihat di bawah ini.

Gain Score $=\frac{\text { Rata }- \text { rata skor Siklus 2-Rata }- \text { rata skor Siklus } 1}{100-\text { Rata }- \text { rata skor Siklus } 1}$

Setelah dihitung maka gain score akan dikategorikan. Pengkategorian ini berdasarkan apa yang diutarakan oleh Puspitorini, Prodjosantoso, Subali, \& Jumadi (2014). Lebih jelasnya dapat dilihat pada tabel 1 dibawah ini.

\begin{tabular}{ll}
\multicolumn{2}{l}{ Tabel 1. Kriteria Gain Score } \\
\hline Gain Score & Kriteria \\
\hline $\mathrm{g} \geq 0,7$ & Tinggi \\
$0,7>\mathrm{g} \geq 0,3$ & Sedang \\
$\mathrm{g}<0,3$ & Rendah \\
\hline
\end{tabular}

\section{HASIL DAN PEMBAHASAN}

Data yang diambil menunjukan peningkatan di setiap siklusnya. Rata-rata skor siswa yang terbesar terdapat pada siklus 3. Rincian dari rata-rata skor dapat dilihat pada tabel 2 di bawah ini.

Tabel 2. Rata-rata skor setiap siklus

\begin{tabular}{ll}
\hline Tahap & Rata-rata \\
\hline Sikus 1 & 59.14 \\
Siklus 2 & 67.28 \\
Siklus 3 & 78.00 \\
\hline
\end{tabular}


Rata-rata skor tersebut kemudian diukur menggunakan rumus gain score dan diinterpretasikan ke dalam kriteria yang tersedia. Berdasarkan hasil perhitungan diperoleh kriteria gain score yang diperoleh yaitu rendah dan sedang. Rinciannya dapat dilihat pada tabel 3 di bawah ini.

Tabel 3. Kriteria Gain Score di setiap siklus

\begin{tabular}{lll}
\hline Tahap & Gain Score & Kriteria \\
\hline Siklus 1 - Siklus 2 & 0.19 & Rendah \\
Siklus 2 - Siklus 3 & 0.32 & Sedang \\
Siklus 1 - Siklus 3 & 0.46 & Sedang \\
\hline
\end{tabular}

Pada tahap perencanaan di setiap siklusnya, sudah dirancang sedemikian rupa sehingga rancangan pembelajaran yang dilaksanakan juga mengandung unsur-unsur yang mendukung peningkatan HOTS. Pada tahap pelaksanaan secara umum berlangsung secara lancar dan baik. Pemutaran video di kelas juga tidak mengalami gangguan yang berarti. Pada saat observasi, guru memperhatikan dan melakukan observasi. Sementara pada tahap akhir, guru dan siswa melakukan evaluasi terhadap kekurangan media dan pembelajaran yang digunakan dalam siklus tersebut. Media yang masih mengalami kekurangan dilakukan penambahan jumlah, agar pemahaman siswa makin bertambah (Merry, Skingsley, Mitchell, \& Orsmond, 2015; Zureick, BurkRafel, Purkiss, \& Hortsch, 2018).

Peningkatan HOTS siswa dipengaruhi oleh penggunaan video pembelajaran berbasis kasus. Video pembelajaran tersebut dapat mempengaruhi HOTS siswa dikarenakan media pembelajaran tersebut merangsang rasa keingintahuan siswa dalam pembelajaran IPA pada materi lingkungan (Garcia, 2015; Khoiriyah \& Husamah, 2018). Siswa yang menonton sebuah tayangan mengenai fakta-fakta yang tersaji di sekitar lingkungannya akan membuat dia menjadi lebih kritis. Hal ini yang menjadi penyebab meningkatnya HOTS siswa tersebut. Selain itu siswa sebaiknya diminta terjun langsung melakukan praktek yang berkaitan dengan lingkungan agar pembelajaran mereka lebih bermakna (Hacieminoglu, 2016; Ichsan \& Mulyani, 2018).

HOTS siswa SD pada dasarnya bisa ditingkatkan dengan berbagai media pembelajaran, seperti video pembelajaran, ebook, website dan media pembelajaran lainnya. Perkembangan teknologi yang begitu cepat mendorong informasi yang tersedia semakin bayak. Informasi tersebut bisa diakses siswa dimana saja dan kapan saja (Ballatore \& Natale, 2016; Reyna, Hanham, \& Meier, 2018). Hal ini membuat pembelajaran pada era modern ini tidak terbatas hanya di kelas. Pembelajaran bisa dilakukan lewat mana saja. Bahkan pembelajaran bisa dilakukan dari jarak jauh (Jiang et al., 2017). Penggunaan video pembelajaran berbasis kasus juga merupakan bentuk upaya dalam menggunakan media pembelajaran yang modern di kelas (Cheung \& Slavin, 2013; Ichsan, Rusdi, \& Sartono, 2017).

Keterampilan HOTS yang harus dimiliki siswa mencakup menganalisis, mengevaluasi, dan mencipta sesungguhnya dapat ditumbuhkan sejak dini. Pada kemampuan menganalisis misalnya, guru bisa menggunakan model pembelajaan ataupun media pembelajaran yang merangsang daya analisis siswa. Terutama untuk masalah lingkungan, hal itu tergolong mudah karena lingkungan yang sudah rusak bisa dikritisi. Arah pembelajaran pada abad 21 tidak hanya meminta siswa memahami konten materi, tapi yang lebih utama adalah mendorong daya kritis dan analisis siswa. Hal ini bisa ditingkatkan dengan menerapkan pembelajaran berbasis pendekatan ilmiah (Djamahar, Ristanto, Sartono, Ichsan, \& 
Muhlisin, 2018; Vieira \& Tenreiro-Vieira, 2016; Vincent-Ruz \& Schunn, 2017).

Kemampuan mengevaluasi juga merupakan komponen HOTS yang harus dilatih sejak dini. Setelah siswa mampu menganalisis masalah lingkungan dibantu dengan media pembelajaran video berbasis kasus, maka siswa diharapkan bisa memberikan penilaian dan membuat pernyataan untuk mengkomentari sebuah kasus tertentu tentang pencemaran lingkungan. Siswa pada jenjang SD dirasa sudah siap untuk belajar memberikan pernyataan kritis, paling tidak untuk lingkungan sekitar tempat tinggalnya. Hal ini dikarenakan tema lingkungan merupakan salah satu topik bahasan yang mudah untuk dilakukan kritik dikarenakan lingkungan akhir-akhir ini sedang mengalami penurunan kualitas (Austgulen, 2016; Haws, Winterich, \& Naylor, 2014; Lekakos, Vlachos, \& Koritos, 2014).

Pada kemampuan tertinggi dari HOTS yaitu mencipta, siswa SD diminta untuk membuat sebuah rancangan alat sederhana untuk mengatasi masalah pencemaran lingkungan. Selain itu mereka diminta membuat sebuah gambar berisi ajakan untuk menjaga lingkungan. Gambar yang mereka buat tidaklah harus bagus, asalkan terlihat rapi dan menarik. Rangsangan untuk membuat sesuatu mulai dari rancangan nya terlebih dahulu mampu membantu meningkatkan HOTS (Aisyah, Salehuddin, Aman, Yasin, \& Mimiko, 2018; Garcia, 2015)

\section{SIMPULAN DAN SARAN}

Berdasarkan hasil penelitian maka dapat disimpulkan bahwa penggunaan video pembelajaran berbasis kasus dapat meningkatkan HOTS siswa SD dalam materi pencemaran lingkungan. Peningkatan ini diperoleh karena video tersebut membantu merangsang daya kritis siswa. Selain itu, permasalahan lingkungan yang diangkat juga memudahkan siswa dalam menganalisis dikarenakan permasalahan tersebut mereka lihat di sekitar lingkungan mereka. Maka disarankan untuk para guru di SDN Jatimulya 02 untuk menggunakan video berbasis masalah dalam pembelajaran.

\section{RUJUKAN}

Afflerbach, P., Cho, B. Y., \& Kim, J. Y. (2015). Conceptualizing and Assessing Higher-Order Thinking in Reading. Theory into Practice, 54(3), 203-212. https://doi.org/10.1080/00405841.20 15.1044367.

Aisyah, A., Salehuddin, K., Aman, I., Yasin, R. ., \& Mimiko, N. (2018). Eliciting Elements of Higher Order Thinking Skills in the Higher Secondary Examination Question Structure in Japan and Malaysia Aznur. In Proceedings of the Regional Conference on Science, Technology and Social Sciences (RCSTSS 2016) (pp. 455-464). Springer Singapore. https://doi.org/10.1007/978-981-130074-5.

Anderson, L. W., Krathwohl, D. R., Airiasian, W., Cruikshank, K. A., Mayer, R. E., \& Pintrich, P. R. (2001). A taxonomy for learning, teaching and assessing: A revision of Bloom's Taxonomy of educational outcomes: Complete edition. New York: Longman.

Austgulen, M. H. (2016). Environmentally Sustainable Textile ConsumptionWhat Characterizes the Political Textile Consumers? Journal of Consumer Policy, 39(4), 441-466. https://doi.org/10.1007/s10603-0159305-5.

Ballatore, A., \& Natale, S. (2016). E-readers and the death of the book: Or, new media and the myth of the disappearing medium. New Media and Society, 18(10), 2379-2394. 
https://doi.org/10.1177/1461444815 586984.

Cheung, A. C. K., \& Slavin, R. E. (2013). The effectiveness of educational technology applications for enhancing mathematics achievement in K-12 classrooms: A metaanalysis. Educational Research Review, 9, 88-113. https://doi.org/10.1016/j.edurev.201 3.01.001.

Djamahar, R., Ristanto, R. H., Sartono, N., Ichsan, I. Z., \& Muhlisin, A. (2018). CIRSA : Designing Instructional Kits to Empower 21 st Century Skill. Educational Process: International Journal, 7(3), 200208.

https://doi.org/10.22521/edupij.2018 .73 .4 .

Dono, J., Webb, J., \& Richardson, B. (2010). The relationship between environmental activism, proenvironmental behaviour and social identity. Journal of Environmental Psychology, 30(2), 178-186. https://doi.org/10.1016/j.jenvp.2009. 11.006.

Fauziyah, L., \& Jailani, J. (2014). Pengembangan perangkat pembelajaran matematika yang menunjang pendidikan karakter siswa kelas IV sekolah dasar. Jurnal Prima Edukasia, 2(2), 149-163. https://doi.org/10.21831/jpe.v2i2.27 15.

Garcia, L. C. (2015). Environmental Science Issues for Higher- Order Thinking Skills (HOTS) Development: A Case Study in the Philippines. In Biology Education and Research in a Changing Planet (pp. 45-54). https://doi.org/10.1007/978-981287-524-2.

Hacieminoglu, E. (2016). Elementary school students' attitude toward science and related variables. International Journal of Environmental and Science Education, 11(2), 35-52. https://doi.org/10.12973/ijese.2016.
$288 \mathrm{a}$.

Haws, K. L., Winterich, K. P., \& Naylor, R. W. (2014). Seeing the world through GREEN-tinted glasses: Green consumption values and responses to environmentally friendly products. Journal of Consumer Psychology, 24(3), 336-354. https://doi.org/10.1016/j.jcps.2013.1 1.002 .

Ichsan, I. Z., \& Mulyani, S. W. W. (2018). Improving Students' Motoric Skills Through Demonstration Method in Recycling Plastic Waste. JPBI (Jurnal Pendidikan Biologi Indonesia), 4(2), 189-194. https://doi.org/10.22219/jpbi.v4i2.5 890.

Ichsan, I. Z., Rusdi, R., \& Sartono, N. (2017). Hasil Belajar Sistem Saraf Menggunakan Film Pendek. Biosfer: Jurnal Pendidikan Biologi, 10(2), 49-59. https://doi.org/10.21009/biosferjpb.1 0-2.7.

Jiang, B., Yang, J., Lv, Z., Tian, K., Meng, Q., \& Yan, Y. (2017). Internet cross-media retrieval based on deep learning. Journal of Visual Communication and Image Representation, 48, 356-366. https://doi.org/10.1016/j.jvcir.2017. 02.011 .

Khoiriyah, A. J., \& Husamah, H. (2018). Problem-based learning: Creative thinking skills, problem-solving skills, and learning outcome of seventh grade students. JPBI (Jurnal Pendidikan Biologi Indonesia), 4(2), 151-160. https://doi.org/10.22219/jpbi.v4i2.5 804.

Kivunja, C. (2014). Teaching Students to Learn and to Work Well with 21st Century Skills: Unpacking the Career and Life Skills Domain of the New Learning Paradigm. International Journal of Higher Education, 4(1), 1-11. https://doi.org/10.5430/ijhe.v4n1p1. 
Lekakos, G., Vlachos, P., \& Koritos, C. (2014). Green is good but is usability better? Consumer reactions to environmental initiatives in ebanking services. Ethics and Information Technology, 16(2), 103-117.

https://doi.org/10.1007/s10676-0149337-6.

Lindfors, E., \& Hilmola, A. (2016). Innovation learning in comprehensive education? International Journal of Technology and Design Education, 26(3), 373389. https://doi.org/10.1007/s10798015-9311-6.

Merry, S., Skingsley, D., Mitchell, P., \& Orsmond, P. (2015). Biology students' perceptions of learning from video exemplars of practical techniques: some lessons for teaching strategies. Innovative Practice in Higher Education, 2(2), $1-14$.

Meyer, A. (2016). Heterogeneity in the preferences and pro-environmental behavior of college students: The effects of years on campus, demographics, and external factors. Journal of Cleaner Production, 112, 3451-3463.

https://doi.org/10.1016/j.jclepro.201 5.10.133.

Motallebzadeh, K., Ahmadi, F., \& Hosseinnia, M. (2018). Relationship between $21 \mathrm{st}$ century skills, speaking and writing skills: A structural equation modelling approach. International Journal of Instruction, 11(3), 265-276. https://doi.org/10.12973/iji.2018.11 319a.

Nesmith, S. M., Wynveen, C. J., Dixon, E. M., Brooks, B. W., Matson, C. W., Hockaday, W. C., ... DeFillipo, J. E. (2016). Exploring Educators' Environmental Education Attitudes and Efficacy: Insights Gleaned from a Texas Wetland Academy. International Journal of Science
Education, Part B: Communication and Public Engagement, 6(3), 303324.

https://doi.org/10.1080/21548455.20 15.1078519.

Puspitorini, R., Prodjosantoso, A. K., Subali, B., \& Jumadi, J. (2014). Penggunaan Media Komik Dalam Pembelajaran Ipa Untuk Meningkatkan Motivasi Dan Hasil Belajar Kognitif Dan Afektif. Jurnal Cakrawala Pendidikan, 3(3). https://doi.org/10.21831/cp.v3i3.238 5.

Reyna, J., Hanham, J., \& Meier, P. (2018). The Internet explosion, digital media principles and implications to communicate effectively in the digital space. E-Learning and Digital Media, 15(1), 36-52. https://doi.org/10.1177/2042753018 754361.

Sadiqin, I. K., Sholahuddin, A., \& Santoso, U. T. (2017). Students, Difficulties on Science Learning with Prototype Problem-Solving Based Teaching and Learning Material :, 100, 279282.

Truelove, H. B., \& Gillis, A. J. (2018). Perception of pro-environmental behavior. Global Environmental Change, 49(February), 175-185. https://doi.org/10.1016/j.gloenvcha. 2018.02.009.

Vieira, R. M., \& Tenreiro-Vieira, C. (2016). Fostering Scientific Literacy and Critical Thinking in Elementary Science Education. International Journal of Science and Mathematics Education, 14(4), 659-680. https://doi.org/10.1007/s10763-0149605-2.

Vincent-Ruz, P., \& Schunn, C. D. (2017). The increasingly important role of science competency beliefs for science learning in girls. Journal of Research in Science Teaching, 54(6), 790-822. https://doi.org/10.1002/tea.21387. 
Vol. 3, No. 2 : Hal 12-18

Edisi September 2018

Yee, M. H., Yunos, J. M., Othman, W., Zureick, A. H., Burk-Rafel, J., Purkiss, J. A., Hassan, R., Tee, T. K., \& Mohamad, M. M. (2015). Disparity of Learning Styles and Higher Order Thinking Skills among Technical Students. Procedia - Social and Behavioral Sciences, 204(November 2014), 143-152. https://doi.org/10.1016/j. sbspro.2015.08.127. \& Hortsch, M. (2018). The interrupted learner: How distractions during live and video lectures influence learning outcomes. Anatomical Sciences Education, 11(4), 366-376. https://doi.org/10.1002/ase.1754. 